Originally published as:

Roux, J.-M., Kaspari, O., Heinrich, R., Hanschmann, N., Grunow, R.

Investigation of a new electrostatic sampler for concentrating biological and non-biological aerosol particles

(2013) Aerosol Science and Technology, 47 (5), pp. 463-471.

DOI: $10.1080 / 02786826.2013 .763896$

This is an author manuscript.

The definitive version is available at: http://www.tandfonline.com/ 


\title{
Investigation of a new electrostatic sampler for concentrating biological and non-biological aerosol particles
}

\begin{abstract}
The detection of airborne pathogens is becoming a subject of great concern in modern day society. Recent studies have shown that electrostatic samplers are suitable for collecting micro-organisms as well as preserving their viability. In most of these studies, flow rates were lower than $12.5 \mathrm{~L} / \mathrm{min}$ or required a concentration stage to increase the flow rate to 100 L/min.
\end{abstract}

In the present study, a single stage electrostatic sampler was developed for an efficient collection of microorganisms at $100 \mathrm{~L} / \mathrm{min}$. The design is based on the positive DC corona between coaxial cylinders to continuously create charged particles as they pass through the sampler. The indoor collection efficiency of the device was investigated by sampling the ambient air particles. The efficiency in collecting live biological samples was determined by sampling live bacterial spores with the collector situated inside an aerosol chamber. It is shown that particles of $0.3-0.35 \mu \mathrm{m}$ are captured with an efficiency of about $86 \%$, whereas cultivable spores of Bacillus thuringiensis are collected with an efficiency of about $94 \%$. Results are compared with an analytical predictive model. The experimental results are similar to the efficiencies previously reported in the literature, however, the current sampler design features a higher flow rate which enables the device to be used as an alarm trigger in a shorter period of time.

Keywords: electrostatic precipitator; high-volume air sampling; bioaerosol; spores

\section{Introduction}

Human exposure to airborne biological agents, is known to cause various illnesses, infections and allergies. Pathogenic organisms such as Bacillus anthracis, are also of great concern to the public because these agents, can be intentionally released with the purpose of causing significant public anxiety, sickness and fatalities. This was demonstrated, with the release of B. anthracis spores in the USA in late 2001. Safeguarding a certain area against biological agents demands detection of pathogenic vegetative bacteria, bacterial spores and viruses by sampling and analysing aerosols within a few minutes in order to trigger a timely alarm, preventing wider exposure of civilians to the danger.

Electrostatic sampling is one of the most efficient ways to collect particles by electrically charging the aerosols and collecting them due to electrostatic forces. Caruana (2011) observed that there relatively few studies have been published on the applicability of electrostatic precipitation to collect bioaerosols. However, interest in electrostatic methods is growing and studies recently showed that it is a suitable method to collect micro-organisms (see Table 1). Compared to collection by impaction methods, advantages of the electrostatic-sampling-based 
method are, lower impaction stress (Mainelis et al. 1999), lower pressure drop and lower power consumption (Tan et al. 2011). Yao demonstrated that electrostatic sampling could achieve culturable bioaerosol concentration levels as much as nine times higher than the BioStage impactor (Yao and Mainelis 2006) and five to ten times higher airborne allergen and toxin concentration levels than the BioSampler (Yao et al. 2009). High concentration rates were also obtained with a smart implementation of the Lotus effect (Barthlott and Neinhuis 1997; Feng et al. 2002) with an ultra hydrophobic surface (Han and Mainelis 2008; Han et al. 2010). Unfortunately, while electrostatic precipitators used as air cleaners work at high flow rates, most of the aforementioned studies are based on devices using a lower flow rate (Table 1) and are therefore not directly comparable.

Although concentrations of intentionally released airborne biological agents may be very high, the background level of pathogen is very low e.g. in areas such as operating rooms where concentrations of bacteria should be lower than $10 \mathrm{CFU}$ per cubic meter (NF S90-351 standard). Monitoring endemic, or intentionally released airborne biological agents therefore, requires high collection efficiencies for particles over a wide range of size and at flow rates of at least $100 \mathrm{~L} / \mathrm{min}$ in order to trigger an alarm within a few minutes. Furthermore, to provide a timely alarm response, the collection and detection methods cannot rely on culturing techniques. Petrovick et al. (2007), pointed out that advanced microbiological sample analysis tools (such as polymerase chain reaction, enzyme linked immunosorbent assay, and others) have to be used. These methods have varying degrees of sensitivityand are conducted in liquid medium.

Electrostatic precipitators (ESP) which are used to collect bioaerosols usually combine a charger stage where particles receive electrical charges from a corona discharge and a precipitator stage where the charged particles are collected under the influence of an electric field (see Table 1). In these configurations the flow rate must be kept low enough to ensure the particles are electrically charged near the coronating electrode(s). Other types of precipitators have been studied by Madsen and Sharma (2007) and by Sillanpää et al. (2008). In the former case, the bio sampler is based on a commercial air cleaner and consists of several collecting cells set side by side. In the latter case, a point to plane corona discharge was studiedwhich takes advantage of the precipitator's length and uses a second wire that allows a second chance for particles to become charged. In both cases, the resulting configurations, whilst easy to construct, are rather complex to model and therefore difficult to optimize.

In this study, computational models provided design guidelines that were used to build a novel electrostatic bio-sampler able to fulfill the aforementioned objectives and constraints. Its efficiency was evaluated by sampling natural airborne particles in an office room and by collecting airborne spores of Bacillus thuringiensis inside an aerosol chamber. Evaluations made on this device are reported and results concerning the crucial step of the sample transfer are shown.

\section{Air sampler design and performance}


Numerous theoretical modelshave been used to evaluate the efficiency of an electrostatic precipitator and have been reviewed by Lawless and Sparks (1985) and Long and Yao (2010). It has been found that the efficiency of the precipitators is always related to the ratio of the convective time $\tau_{c}$ of the air flow and the transit time $\tau_{m}$ of particles migrating to the collecting electrode:

$$
\frac{\tau_{c}}{\tau_{m}}=\frac{\omega}{L} \times \frac{h}{v}=\frac{\omega A}{Q}
$$

where $\omega$ is the migration velocity, $v$ the gas velocity, $L$ the distance between electrodes, $h$ their length, $A$ the collecting electrode area and $Q$ the flow rate. According to the original Deutsch formula the theoretical efficiency $\eta_{t h}$ is given by:

$$
\eta_{t h}=1-\exp (-\omega A / Q)
$$

These equations indicate a possible means for increasing collection efficiency, namely by increasing the migration velocity or collection area, or by decreasing gas velocity (Jaworek et al. 2007). The latter can be achieved by maximising the cross section area of the collector. However, unlike air cleaners, precipitators that need to provide an analyzable sample, must feature a small collection surface in order to reduce the amount of water needed for rinsing and thereby achieving high concentrations of the collected particles. These considerations suggest cylindrical configurations as good candidates for the sampler design.

The electrostatic precipitator built for this study is based on the positive DC corona between coaxial cylinders as shown in Figure 1. Since Leonard (1983) and Yamamoto (1989) emphasize the importance of controlling the quality of flow characteristics, an internal diameter $D$, of $650 \mathrm{~mm}$ was chosen as a compromise between the flow regime, which should be laminar to maximise the capture efficiency, and the flow rate, that should be as high as possible. The radius was subsequently defined by choosing a Reynolds number slightly lower than 2000 for the flow rate of $100 \mathrm{~L} / \mathrm{min}$. A wire diameter of $100 \mu \mathrm{m}$ was chosen, since a smaller one, although leading to a decrease of the onset voltage and an increase of the space charge density, would have been difficult to handle. The electrodes' length $h$ was chosen from the compromise between the need for compactness and the electric field strength required.

In the design, high voltage is applied on the stainless steel wire with a $15 \mathrm{kV}$ generator while the outer cylinder is grounded. The air flows from top to bottom between the two electrodes and makes its way out through 6 bevelled tubes which connect the collection chamber to the basis in a slight depression caused by a blower (Figure 1). When sampling is finished, the collection area on the inside of the cylinder is rinsed with an aqueous solution injected through 24 nozzles located at the top of the collecting chamber. The rinsing liquid flows over the stainless steel collecting electrode to transfer the captured particles intohydrophobic bevelled tubes and is accumulated in a hydrophobic cone. Afterwards a peristaltic pump draws off the collected liquid. This rinsing step relies on several parameters which were studied to allow optimization: the volume of liquid injected, the number of flushes, and the type and concentration of surface active agent used to decrease surface tension of the rinsing liquid and improve wetting of the collecting surface. 
In this axisymmetric configuration, the space-charge-influenced electric field is calculated analytically (Townsend 1914). The method is given in the Supplemental Information. The field strength decreases sharply as it moves away from the wire and becomes more uniform (Figure S1, see online supplemental information). The charger and precipitator stages are therefore arranged in parallel rather than sequentially.

The sampler efficiency can be evaluated using equation (2) with the migration velocity given by:

$$
\omega=\frac{Q_{p} E_{t h}}{3 \pi \mu d_{p}} C_{m}
$$

where $Q_{p}$ is the particles mean charge, $d_{p}$ their diameter, $E_{t h}$ the theoretical electric field strength, $\mu$ the gas dynamic viscosity and $C_{m}$ the Cunningham factor, which is used to account for noncontinuum effects when calculating the drag on small particles. It is given by the equation:

$$
C_{m}=1+2.54\left(\frac{\lambda}{d_{p}}\right)+0.8\left(\frac{\lambda}{d_{p}}\right) e^{-0.55 \frac{d_{p}}{\lambda}}
$$

where $\lambda$ is the mean free path.

It is assumed that particles get the charge $Q_{p}$ (Hinds 1999; Mizuno 2000; Saiyasitpanich et al. 2006):

$$
Q_{p}=\pi \varepsilon_{0}\left(\frac{3 \varepsilon_{r}}{\varepsilon_{r}+2}\right) E_{t h} d_{p}+\frac{2 \pi \varepsilon_{0} d_{p} k T}{e} \ln \left(1+\frac{d_{p} \bar{c} e^{2} N t}{8 \varepsilon_{0} k T}\right)
$$

where $\varepsilon_{r}$ is the relative permittivity of particles, $\bar{c}$ is the mean thermal speed of the ions, $N$ is the concentration of ions evaluated by computing the space charge density $\rho_{t h}$ from Townsend (1914) model, $k$ is Boltzmann's constant, $T$ is temperature, $e$ is the electronic charge and $t$ is the gas residence time. The latter parameter may be estimated from the flow rate $Q$ and the sampler volume:

$$
t=\frac{\pi(D / 2)^{2} h}{Q}
$$

The dielectric constant $\varepsilon_{r}$ of particles is unknown. However, for dielectric particles the value normally lies between 1 and 10 (Saiyasitpanich et al. 2006) but may be higher. Droplets of water would have a relative permittivity of 80 , however, this parameter affects only the first factor of equation (5) which value lies between 1 and 3. An average relative permittivity of 4 was adopted and its influence on results is not significant.

The electric field strength $E_{t h}$ and the space charge density $\rho_{t h}$ values can be computed from the Townsend (1914) model instead of pseudo-homogenous parameters. The electric field (Figure 2) and the space charge density decrease from the wire to the counter-electrode. Since they become nearly constant at $1 \mathrm{~cm}$ distance from the wire, those values were evaluated in the middle of the gas stream. Other values used in computations are given in Table S1 (see online supplemental information).

\section{Experimental setup and technique}




\subsection{Evaluation of the physical capture efficiency}

The physical capture efficiency of the sampler was determinedby sampling natural airborne particles in an $8.1 \times 11.9 \times 2.8 \mathrm{~m}$ office room (Figure S2, see online supplemental information), where particle concentrations were quite stable over a few hours. These ambient concentrations were measured during five minutes by an optical particle counter (model 1.109 , Grimm Technologies) before the efficiency evaluations were made.

The evaluations followed a commonly used protocol (Yao and Mainelis 2006) with an experimental setup which is shown schematically in Figure S3 (see online supplemental information). First, a downstream particle concentration $C(V=0, Q)$ was measured by the optical particle counter without applying the collection voltage. Next, the power supply was switched on and downstream particle concentration $C(V, Q)$ was measured by the same device. Measurements with and without collection voltage applied were carried out over 5 minute periods . For each evaluation, the sampler was operated at flow rates $Q$ from 40 to $90 \mathrm{~L} / \mathrm{min}$ without any applied voltage $V$ and afterwards with a voltage $V$ of $7.4 \mathrm{kV}, 10 \mathrm{kV}, 12.4 \mathrm{kV}$ and $15 \mathrm{kV}$. Each evaluation was followed by a particle collection for 4 hours at maximum flow rate and collection voltage, after which the sampler's collecting electrode was cleaned with a flush of water. This protocol was repeated eight times in order to observe and quantify the sampler's degradation.

The Grimm counter operates at a standard flow rate of $1.2 \mathrm{~L} / \mathrm{min}$ and measures particle concentrations in sixteen size-dependent channels starting at $0.3 \mu \mathrm{m}$. For all testing conditions the sampling was isoaxial and near-isokinetic, while the flow rate $Q$ was read on a mass flow meter (model 4199, TSI). The probe used in these experiments lowers the maximum flow rate by about $10 \mathrm{~L} / \mathrm{min}$ so the physical efficiency was evaluated up to $90 \mathrm{~L} / \mathrm{min}$ instead of $100 \mathrm{~L} / \mathrm{min}$.

Ambient particle concentrations measured prior to the evaluations were compared to the mean downstream particle concentration without any voltage applied $\bar{C}(V=0, Q)$. This first result would indicate whether the sampler head does or does not alter the relative proportion of particles. Ideally, downstream particle concentrations are equal to ambient concentrations. Next, the average physical capture efficiency was calculated as follows:

$$
\eta_{p h y s}(V, Q)=100 \cdot\left(1-\frac{\bar{C}(V, Q)}{\bar{C}(V=0, Q)}\right)
$$

\subsection{Evaluation of the biological collection efficiency 3.2.1. Bioaerosol production}

The aerosol chamber chosen to simulate the experimental environment consists of a microbiological glove box (Ehret; Emmendingen, Germany) (Figure S2, see online supplemental information) equipped with a ventilation system, HEPA filtration of in- and outgoing air as well as a wall mounted fan to allow turbulence of injected aerosols. The 2.17 $\mathrm{m} \times 0.95 \mathrm{~m} \times 2.73 \mathrm{~m}$ device features an inner volume of 1.1 cubic meters, an airlock to allow safe transfer of samples and six openings with gloves to allow manipulations of devices in the 
interior. In addition, a connected hydrogen peroxide generator (PEA; Hannover, Germany) allows effective sterilization between experiments.

Spores of Bacillus thuringiensis DSM350, were prepared according to European norm (EN) 14347:2005 and aerosols were produced via ultrasonic vaporization of a solution containing 1 x $10^{7}$ spores per ml. In more detail, the solution was injected via a Vit-Fit (HP) injection system (Lamda; Baar, Switzerland) through an ultrasound nozzle (Sono-Tek; Milton, USA) and nebulized by ultrasonic pulses with a power of 2.3 watts achieving an average particle size of $0.8 \mu \mathrm{m}$.

In prior experiments it was observed that, when producing aerosols of spore solutions with the concentration used in these experiments, only $1.7 \%$ of aerosol particles are larger than $2 \mu \mathrm{m}$ and none larger than $5 \mu \mathrm{m}$ in diameter (Results obtained using a GRIMM counter). We could not observe a noticeable amount of decay in concentration during 3 min since such small particles remain airborne for a long time.

Spore survival was determined by collecting the aerosol in a reaction tube directly from the ultrasound nozzle during aerosolization. Numbers of surviving spores were determined by plate counting and the percentage of survival was calculated by comparing results to the initial concentration of the spore solution before aerosolization, which was taken as a reference.

\subsubsection{Sample collection and analysis}

The air sampler was set up inside the aerosol chamber (Figure S4, see online supplemental information) and $1 \mathrm{ml}$ of a $B$. thuringiensis spore solution $\left(1 \times 10^{7}\right.$ spores) was injected and vaporized with a constant speed of $870 \mu \mathrm{l} / \mathrm{min}$. An even distribution of the aerosol inside the chamber was ensured by an integrated fan. The sampler was started together with the aerosol injection at the maximum flow rate of $100 \mathrm{~L} / \mathrm{min}$ and a voltage of $15 \mathrm{kV}$. Sample collection was carried out over a three minute period after which collected spores were eluted by injecting a rinsing solution.

A serial dilution of obtained samples was plated out on tryptic soy agar and incubated at $37^{\circ} \mathrm{C}$ for 24 hours. Colony forming units (CFU) were counted and median values were determined from at least two collections. Final values were calculated by taking into account that only a fourth of the chamber volume was sampled in the given time and that on average only $51.7 \%$ $( \pm 1.1 \%)$ percent of the spores survived the aerosolization process (determined by plate counting of samples taken directly from the nebulization nozzle, data not shown). The maximally collectable amount of spores $\left(N_{\max }\right)$ was then calculated as follows:

$$
N_{\max }=\left(\frac{N_{C F U}}{1,93}\right) \times \frac{(Q \times t)}{V_{c}}
$$

where $N_{C F U}$ is the used spore count (determined by plate counting before aerosolization), $Q$ is the sampler flow rate (in these experiments: $100 \mathrm{~L} / \mathrm{min}$. since the iso-kinetic probe is not used), $t$ is the sampling time in minutes (in these experiments: $3 \mathrm{~min}$.) and $V_{c}$ the volume of air inside the chamber (in this case: $1100 \mathrm{~L}$ ).

The biological efficiency of the air sampler was calculated as follows: 


$$
\eta_{\text {bio }}=\frac{N}{N_{\max }}
$$

where $N$ is the spore count resulting from the experiment and determined by plate counting and $N_{\max }$ is the theoretically calculated maximal collectable spore count.

The calculated numbers represent the efficiency of the air sampler for collecting living spores. Non-viable spores which are also sampled and eluted, do not provide countable numbers with this culture method, but might be useful for future analysis methods in order to trigger a timely alarm.

\section{Results \\ 4.1. Physical efficiency}

The mean ambient particle concentrations as well as the mean downstream particle concentration measured without any voltage $\bar{C}(V=0, Q)$ show that ambient concentrations are rather stable and that the sampler does not filter particles when run without high voltage (see Table S2 given in Supplemental Information). The collection phenomenon is therefore due to the high voltage effect alone.

The capture efficiencies $\eta_{t h}(V, Q)$ and $\eta_{p h y s}(V, Q)$, for the smallest particles enumerated by the optical counter $(0.3-0.35 \mu \mathrm{m})$, were calculated respectively with equations (2) and (7). Results are shown in Figure 2 (additional results are shown in Table S3 and Table S4 given in Supplemental Information). Experimental points were averaged over four trials and are distributed according to the two parameters $(V, Q)$ controlled in the experiments so that the result is a 3-D analysis. Level curves were added to highlight the efficiency on a $2 \mathrm{D}$ plot which is easier to interpret. The measured values proved to be higher than those predicted, especially when applying a low voltage and using a high flow rate.

The evolution of the capture efficiencies $\eta_{p h y s}(V, Q)$ over a succession of measurements and after 4 hours operations at full power are shown in Figure 3. Two distinct groups of results were apparent . From the first to the fourth trial, the obtained results were very similar. At the maximum voltage, the sampler operates with an efficiency of $86 \% \pm 0.6 \%$ for the smallest particles $(300-350 \mathrm{~nm})$ and $95 \% \pm 5.1 \%$ for particles such as spores $(0.8-1 \mu \mathrm{m})$. In subsequent trials the sampler's efficiency appears to decrease. Inspection of the wire at the end of the experiments showed that the surface was covered by thin filaments when compared with a pristine one (Fig. 4). It is proposed that the filaments have grown in the surrounding plasma.

\subsection{Biological efficiency}

\subsubsection{Determination of suitable rinsing solution}


The sampler's biological efficiency was evaluated by using a $15 \mathrm{ml}$ flush of different rinsing solutions (Fig. 5). Indicated numbers represent the maximum percentage of living spores that are collectible. Best results were achieved when using 1\% SDS (Sodium Dodecyl Sulfate) as rinsing solution followed by $0.2 \%$ SDS and Alcapur $\mathrm{N}^{\circledR}$, a commercially available tenside containing Sodium Lauryl Sulphate, while Triton X-100 and Tween 20 seemed to be less effective.

\subsubsection{Improvement of the rinsing method}

After determining the most effective type of rinsing solution, the next step consisted in finding the best rinsing method with the same conditions as before. Since a solution of $1 \%$ SDS proved to be most effective in our previous experiments, elution of collected spores was carried out using $1 \%$ SDS as rinsing solution with flushes of different volumes and number (Fig. 6).

The best results regarding elution efficacy were obtained when a flush of $15 \mathrm{ml}$ was followed by a second one of $10 \mathrm{ml}$. This yielded an average result of $94 \%$ of collected living spores which is consistent with the average physical efficiency measured for particles of about $800 \mu \mathrm{m})$. However, flushes of $15 \mathrm{ml}$ followed by $5 \mathrm{ml}$ was considered as the best method, since it was possible to collect $86 \%$ of aerosolized spores while reducing the amount of liquid by $20 \%$. Three flushes of $5 \mathrm{ml}$ each was still found to be quite effective and yielded $64 \%$ of collectible living spores. In a further test five flushes of $3 \mathrm{ml}$ rinsing solution each, was found to be ineffective at collecting the spores because the small volume of rinsing liquid is not enough to cover the collection matrix efficiently.

\section{Discussion}

Commonly used bioaerosol samplers are impingers that have a $50 \%$ cut-off diameter of approximately $300 \mathrm{~nm}$ (Hogans et al. 2005) with a flow rate of about $12.5 \mathrm{~L} / \mathrm{min}$. The physical capture efficiency of the present electrostatic air sampler is very high compared to these conventional devices. The collector configuration presented here was previously used to collect ultra-fine inorganic particles (see Table S5 given in Supplemental Information available online with this publication) and offers numerous advantages over other collection systems. The coronating electrode extends over the whole precipitator length so that particles obtain charges continuously as they pass through the inside of the sampler. This feature gives an advantage to the present sampler compared to a two-stage one. It should also be noted that a higher collection efficiency, or a higher flow rate, might aslo be obtained by increasing the length of the precipitator. An additional advantage derives from the axial symmetry of the configuration, which facilitates collection modelling and numerical optimisations of the sampler.

Saiyasitpanich et al. (2006) obtained comparable collection efficiencies in a wire-cylinder precipitator where the air flow was highly turbulent ( $\operatorname{Re} \sim 16000-66000)$. Also Zhuang et 
al. (2000) obtained similar results to the present study using a similar configuration $(\operatorname{Re} \sim 570$ -1140), but with a higher flow rate because of the larger diameter. It should be noted that the diversity of the designs used for biosamplers, makes direct comparisons quite difficult and the flow rates reported in most of the previous studies dedicated to bioaerosols were much lower (see Table 1) than reported in this study. Therefore, the use of models allows better comparison and in this study, a simple model was used as a predictive tool, comparable to the method of Saiyasitpanich et al. (2006). It was also tried to improve the theoretical results obtained by the latter while keeping the model analytical and simple for practical work.

Results shown in Figure 3 indicate that the sampler's efficiency on 300-350nm indoor ambient air particles was about $86 \% \pm 0.6 \%$ at a flow rate of $90 \mathrm{~L} / \mathrm{min}$. Han et al. (2009) obtained a comparable efficiency but the flow rate in the collecting cell was much lower, their sampler being composed of a virtual impactor to concentrate particles from a $100 \mathrm{~L} / \mathrm{min}$ flow to a $3 \mathrm{~L} / \mathrm{min}$ flow. Moreover one should note that the electric field used by Han et al. was 10 $\mathrm{kV} / \mathrm{cm}$ in the PM-ESP and $5 \mathrm{kV} / \mathrm{cm}$ in the Cell-ESP while the electric field on the collecting electrode of the present sampler is about $3.75 \mathrm{kV} / \mathrm{cm}$ (Figure S1). The reduction in the electric field should reduce the harmful effects of the discharge on biological agents.

In the present study, after four measurements of electrostatic collection a small decrease in physical collection efficiency was observed. This was followed by a collection of four hours duration at maximum voltage and flow rate (Figure 4). In subsequent measurements there was a larger decrease in collection efficiency observed. Since each measurement takes about $2 \mathrm{~h}$, the larger decrease appeared after $24 \mathrm{~h}$ of operation. The collection electrode was cleaned manually before each test in order to exclude an accumulation of particles on it. It is assumed that the observed decrease is correlated to the deterioration of the coronating wire surface shown in Figure 6. This deterioration of the wire is a known effect and can lead to a discharge extinction preventing the sampler from collecting particles anymore (Nashimoto 1988; Davidson and McKinney 1998). This effect poses a weakness of electrostatic samplers that has to be considered when defining their maintenance. Further technical development should find a way to preserve or regenerate the coronating electrode.

The collection efficiencies predicted using values based on the Deutsch model, proved to be lower than the measured ones. This is consistent with previous studies (Riehle and Löffler 1995; Park and Chun 2002; Saiyasitpanich et al. 2006; Li et al. 2010). However, a better accuracy was expected since the electric field and the space charge density variation were investigated and computed with Townsend's analytical model. Values used in the present study should have been more relevant than pseudo-homogenous ones such as $\bar{E}_{t h}=2 \mathrm{~V} / \mathrm{D}$ for the electric field, but in practice they did not improve the performance prediction. Saiyasitpanich et al. (2006) noticed that a very good correlation between theoretical and experimental results can be obtained, when the electric field used in computations was slightly higher than the pseudo-homogeneous one, assuming an effect of the space charge density on the electric field. But in the present study, it is shown that charges stabilize the electric field to a value of $3.75 \mathrm{kV} / \mathrm{cm}$ (shown on Fig. S1), which is lower than the average one $(4.62 \mathrm{kV} / \mathrm{cm})$, when the applied voltage is $15 \mathrm{kV}$. Saiyasitpanich et al. assumed also the secondary flows induced by the ionic wind to be able to improve collection. However, the influence of the ionic wind is complex and may reduce the efficiency of samplers (Liang and Lin 2007). While the physical phenomena are well known and understood, their interactions 
and the subsequent results are very complex. Understanding has now to be improved by a numerical model of a wire-tube precipitator (Farnoosh et al. 2011).

The parametric study of the collecting electrode flushes show that this step is not straightforward and is is crucial in optimising the collection performance. Han $(2008 ; 2010)$ highlighted that recovery efficiency depends on the particles and the rinsing procedure used, achieving a collection efficiency of $65 \pm 7 \%$ determined by microscopy and $54 \pm 3 \%$ determined by whole-cell QPCR for B. subtilis. According to the rinsing protocol, the collection efficiency obtained by plate counting in the present study ranges from $57 \%$ to $94 \%$ when at least $15 \mathrm{ml}$ of liquid is used. Such a volume is commonly used in samplers such as the All Glass Impinger 30 (ACE Glass), the BioSampler® (SKC) and the Coriolis ${ }^{\circledR}$ (Bertin) but it is much higher than volumes used by Han (2008; 2010). The amount used therefore is a compromise between the recovery efficiency and the sample volume.

The method of ultrasound aerosolization utilized in these tests can also be considered as very useful since it combines a high survival rate of the bio-agents with a small average particle size. With this technique we were able to achieve an average spore survival rate of $51.7 \%$. This is a a very good survival rate since it has been reported that aerosolization has a dramatic effect on viability of bacteria and often leads to loss of several log-levels (Heidelberg et al. 1997, Thomas et al. 2008). Also, by producing an average particle size of $0.8 \mu \mathrm{m}$ it can be ensured that the bacterial aerosol consists of single particles, since spore clumping would have modified the obtained results.

\section{Conclusion}

In this study, a single stage electrostatic sampler was developed for an efficient collection of microorganisms at a flow rate of $100 \mathrm{~L} / \mathrm{min}$. The design based on a charger and a precipitating stage set side by side in a cylindrical configuration is very efficient and results show that particles are collected while being subjected to an electrostatic field lower than in previous studies. Indeed, submicron particles of $0.3-0.35 \mu \mathrm{m}$ are captured with an efficiency of about $86 \%$ at a flow rate of $90 \mathrm{~L} / \mathrm{min}$ and field strength of about $3.75 \mathrm{kV} / \mathrm{cm}$, a value lower than in comparable studies. The biological efficiency was investigated with spores of Bacillus thuringiensis. At the maximum flow rate of $100 \mathrm{~L} / \mathrm{min}$, plate counting showed that an efficiency of $94 \%$ is achievable. However, since the sampler is able to perform an efficient collection of $0.3-0.35 \mu \mathrm{m}$ particles, a wider range of airborne biological agents should be collectible, ranging from viruses to fungi. Following Han's $(2008 ; 2010)$ investigations, it was shown that transfer of biological particles is highly dependant on the composition and volume of the rinsing buffer, while best results were obtained with SDS.

Future developments will focus on (1) modelling the sampler's collection efficiency to optimise the present design and (2) integrating the sampler as the first stage of a detection system for airborne bio agents.

\section{Acknowledgments}


The authors gratefully acknowledge the support of this work by the European Commission under FP7 project BioProtect. Jean-Maxime Roux would like to thank Martine Cochet of the CEA-Leti for analysing the discharging wire surface with electronic microscopy. Oliver Kaspari would like to thank Horst Windt and Wolfgang Koch of the Fraunhofer-Insitut für Toxikologie und experimentelle Medizin (Hannover) for implementation of the aerosolization devices and Karin Lemmer for previous work on the aerosol chamber. The authors wish also to thank Dom Cupertino and Kay McClean from C-Tech Innovation for their contribution.

\section{References:}

Barthlott, W., Neinhuis, C. (1997). Purity of the sacred lotus, or escape from contamination in biological surfaces, Planta, 202 (1), 1-8

Caruana, D.J. (2011). Detection and analysis of airborne particles of biological origin: present and future, Analyst, 136, 4661-4652

Davidson, J.H., McKinney, P.J. (1998). Chemical Vapor Deposition in the Corona Discharge of Electrostatic Air Cleaners, Aerosol Science and Technology, 29, 102-110

Farnoosh, N., Adamiak, K., Castle, G.S.P. (2011). 3D numerical study of wire-cylinder precipitator for collecting ultrafine particles from diesel exhaust, IEEE Industry Applications Society Annual Meeting (IAS), 1-5

Feng, L., Li, S., Li, Y., Li, H., Zhang, L., Zhai, J., Song, Y., Liu, B., Jiang, L., Zhu, D. (2002). Super-Hydrophobic Surfaces: From Natural to Artificial, Advanced Materials, 14 (24), $1857-$ 1860

Han, T., Mainelis, G. (2008). Design and development of an electrostatic sampler for bioaerosols with high concentration rate, Aerosol Science, 39, 1066-1078

Han, B., Hudda, N., Ning, Z., Kim, Y.J., Sioutas, C. (2009). Efficient Collection of Atmospheric Aerosols with a Particle Concentrator - Electrostatic Precipitator Sampler, Aerosol Science and Technology, 43, 757-766,

Han, T., An, H.R., Mainelis, G. (2010). Performance of an Electrostatic Precipitator with Superhydrophobic Surface when Collecting Airborne Bacteria, Aerosol Science and Technology, 44, 339-348

Heidelberg, J.F., Shahamat, M., Levin, M., Rahman, I., Stelma, G., Grim, C., Colwell, R.R. (1997). Effect of Aerosolization on Culturability and Viability of Gram-Negative Bacteria; Applied and environmental microbiology, 63 (9), 3585-3588

Hinds, W.C. (1999). Aerosol Technology: Properties, Behavior, and Measurement of Airborne Particles, 2nd Edition. Wiley, New York

Hogan Jr, C.J., Kettleson, E.M., Lee, M.-H., Ramaswami, B., Angenent, L.T. and Biswas, P. (2005). Sampling methodologies and dosage assessment techniques for submicrometre and ultrafine virus aerosol particles. Journal of Applied Microbiology, 99, 1422-1434

Lawless, P.A., Sparks, L.E. (1985). Review of mathematical models for ESPs and comparison of their successes, Technical Report of the U.S. Department of Energy, 513-522

Leonard, G.L., Mitchner, M., Self, S.A. (1983). An experimental study of the electrohydrodynamic flow in electrostatic precipitator, J. Fluid. Mech., 127, 123-140

Li, C., Liu, S., Zhu, Y. (2010). Determining Ultrafine Particle Collection Efficiency in a Nanometer Aerosol Sampler, Aerosol Science and Technology, 1027-1041 
Liang, W.J., Lin, T.H. (1994). The Characteristics of Ionic Wind and Its Effect on Electrostatic Precipitators, Aerosol Science and Technology, 20(4), 330-344

Long, Z., Yao, Q. (2010). Evaluation of various particle charging models for simulating particle dynamics in electrostatic precipitators, Journal of Aerosol Science, 41, 702-718

Madsen, A.M., Sharma, A.K. (2008), Sampling of High Amounts of Bioaerosols Using a High-Volume Electrostatic Field Sampler, Ann. Occup. Hyg., 52(3), 167-176

Mainelis, G., Grinshpun, S. A., Willeke, K., Reponen, T. (1999). Collection of Airborne Microorganisms by Electrostatic Precipitation, Aerosol Science and Technology, 30, 127-144

Mainelis, G., Adhikari, A., Willeke, K., Lee, S.A., Reponen, T., Grinshpun, S.A. (2002). Collection of airborne microorganisms by a new electrostatic precipitator, Aerosol Science, $33,1417-1432$

Mizuno, A. (2000), Electrostatic Precipitation, IEEE Transactions on Dielectrics and Electrical Insulation, 7(5), 615-624

Nashimoto, K. (1988). Growth behavior of silicon oxide on wire anode of positive corona discharge, Japanese Journal of Applied Physics, 27(8), 1381-1385

NF S90-351 (2003). Health care establishments - Cleanrooms and associated controlled environments - Requirements for the control of airborne contamination

Park, J-H., Chun, C-H. (2002). An improved modelling for prediction of grade efficiency of electrostatic precipitators with negative corona, Journal of Aerosol Science, 33 (4), 673-694 Petrovick, M.S., Harper, J.D., Nargi, F.E., Schwoebel, E.D., Hennessy, M.C., Rider, T.H., Hollis, M.A. (2007). Rapid Sensors for Biological-Agent Identification, Lincoln Laboratory Journal, 17(1), 63-84

Riehle, C., Löffler, F., (1995). Grade Efficiency and Eddy Diffusivity Models, J. Electrostat., 34, 401-413.

Saiyasitpanich, P., Keener, T.C., Lu, M., Khang, S.J., Evans, D.G. (2006), Collection of Ultrafine Diesel Particulate Matter (DPM) in Cylindrical Single-Stage Wet Electrostatic Precipitators, Environ. Sci. Technol., 40, 7890-7895

Sharma, A.K., Wallinb, H., Jensen, K.A. (2007). High volume electrostatic field-sampler for collection of fine particle bulk samples, Atmospheric Environment, 41, 369-381

Sillanpää, M., Geller, M.D., Phuleria, H.C., Sioutas, C. (2008). High collection efficiency electrostatic precipitator for in vitro cell exposure to concentrated ambient particulate matter (PM), Aerosol Science, 39, 335 - 347

Tan, M., Shen, F., Yao, M., Zhu, T. (2011). Development of an Automated Electrostatic Sampler (AES) for Bioaerosol Detection, Aerosol Science and Technology, 45, 1154-1160

Tilmatine, A., Gouri, R., Miloua, F., Kadous, N., Medles, K. Dascalescu, L. (2008). Optimisation of the intermittent operation of a wire-cylinder electrostatic precipitator, Journal of Physics: Conference Series, 142(1), 12-19

Thomas, R.J., Webber, D., Sellors, W., Collinge, A., Frost, A., Stagg, A.J., Bailey, S.C., Jayasekera, P.N., Taylor, R.R., Eley, S., Titball, R.W. (2008). Characterization and Deposition of Respirable Large- and Small-Particle Bioaerosols, Applied and environmental microbiology, 74 (20), 6437-6443

Townsend, J.S. (1914). The potentials required to maintain currents between coaxial cylinders, Philosophical Magazine and Journal of Science, 6 (28), 83-90

Yamamoto (1989). Effects of turbulence and electrohydrodynamics on the performance of electrostatic precipitators, Journal of Electrostatics, 22(1), 11-22

Yao, M., Mainelis, G. (2006). Utilization of natural electrical charges on airborne microorganisms for their collection by electrostatic means, Aerosol Science, 37, 513-527 
Yao, M., Zhang, H., Dong, S., Zhen, S., Chen, X. (2009). Comparison of electrostatic collection and liquid impinging methods when collecting airborne house dust allergens, endotoxin and (1,3)- $\beta$-d-glucans, Aerosol Science, 40, 492-502

Zhuang, Y., Kim, Y.J., Lee, T.G., Biswas, P. (2000). Experimental and theoretical studies of ultra-fine particle behavior in electrostatic precipitators, Journal of Electrostatics, 48, 245-260

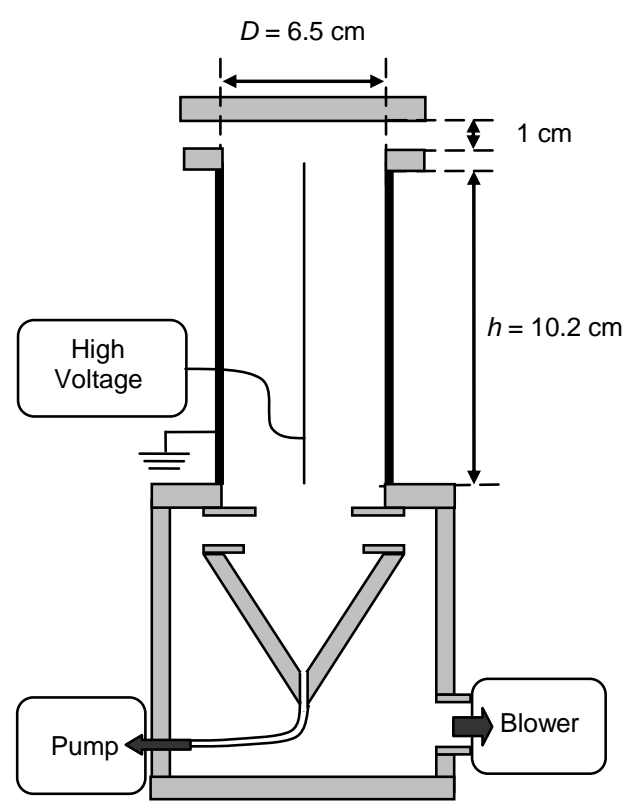

Fig. 1: Schematic drawing of the sampler. 
Theoretical efficiency on $0.35 \mu \mathrm{m}$ particles

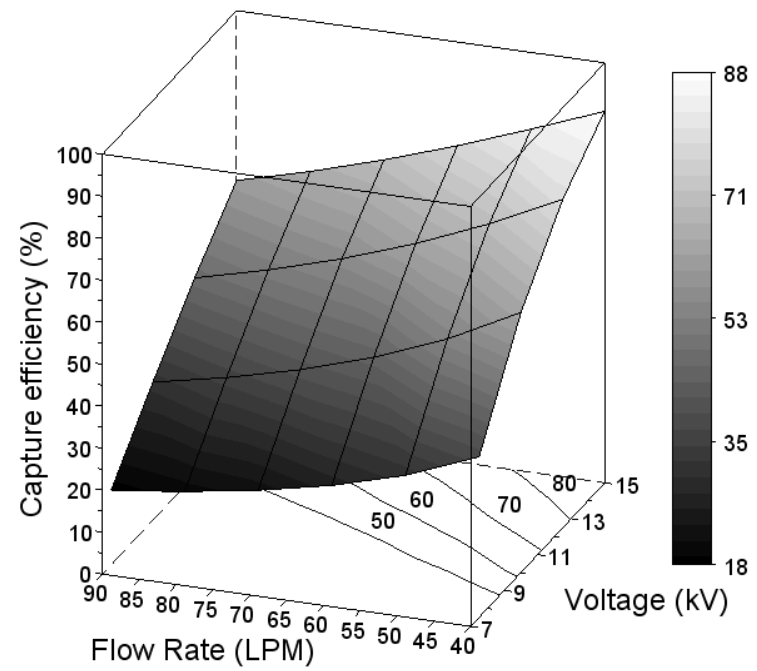

Experimental efficiency on $0.30-0.35 \mu \mathrm{m}$ particles

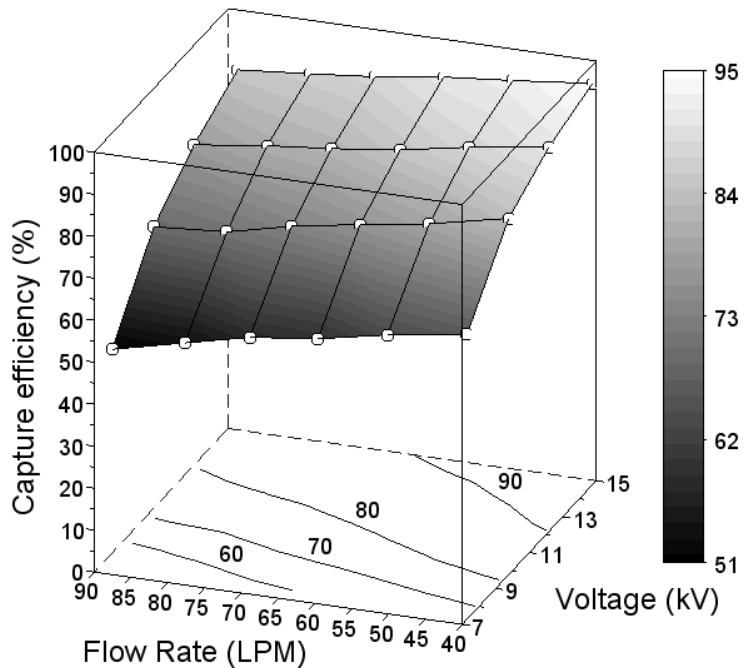

Fig. 2: Air sampler efficiency evaluated theoretically (left) and experimentally (right) on 0.3-0.35 $\mu \mathrm{m}$ particles as a function of the flow rate and the applied voltage. Experimental values were averaged over four consecutive trials separated by a 4 hour operation at full power. These averaged experimental points are represented by circles on the figure.

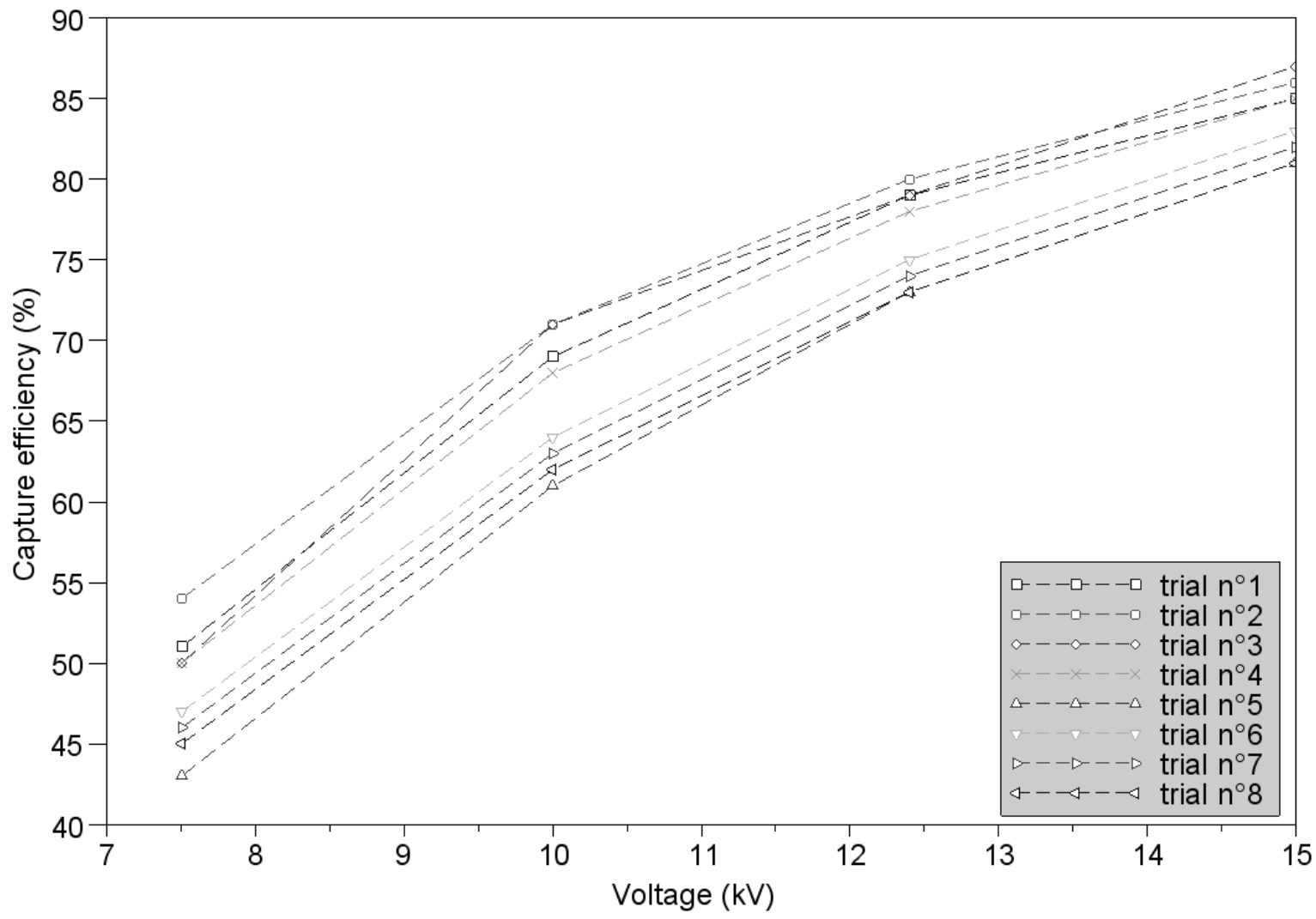

Fig. 3: Air sampler efficiencies measured on 0.3-0.35 $\mu \mathrm{m}$ particles at a flow rate of $90 \mathrm{LPM}$ as a function of the applied voltage. Trials were separated by a 4 hour operation at full power to investigate the stability of the results. 

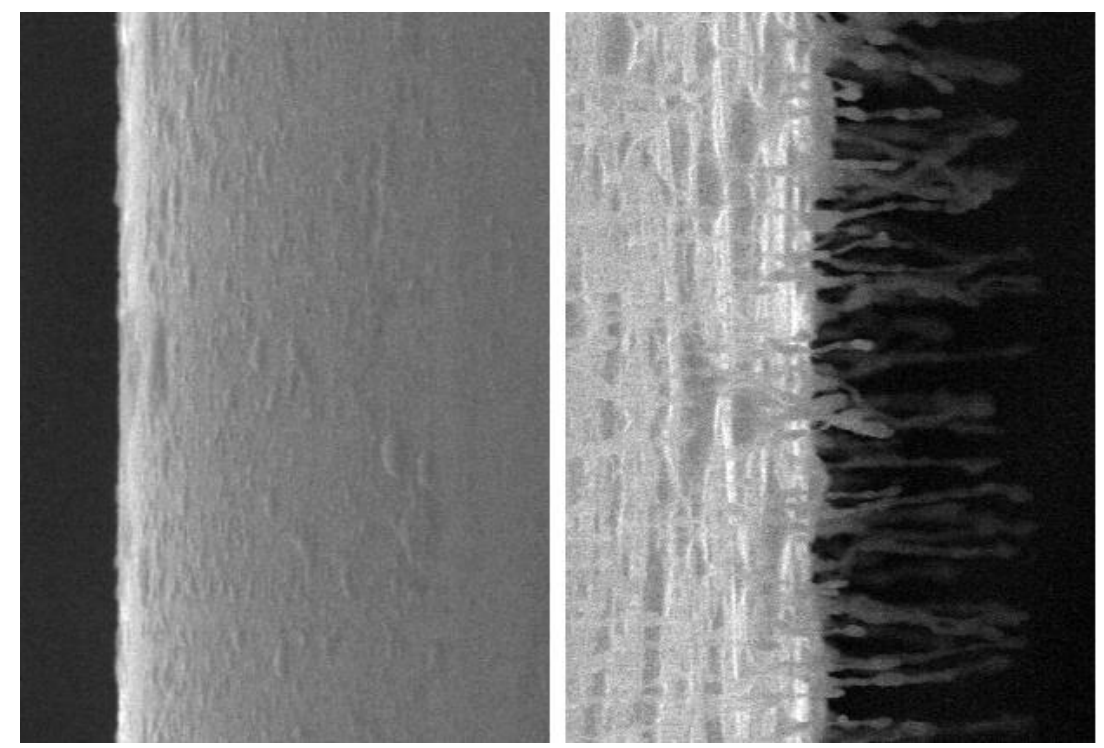

Fig. 4: Picture of the stainless steel wire: left, an unused wire; right, the wire after operation in the endurance test.

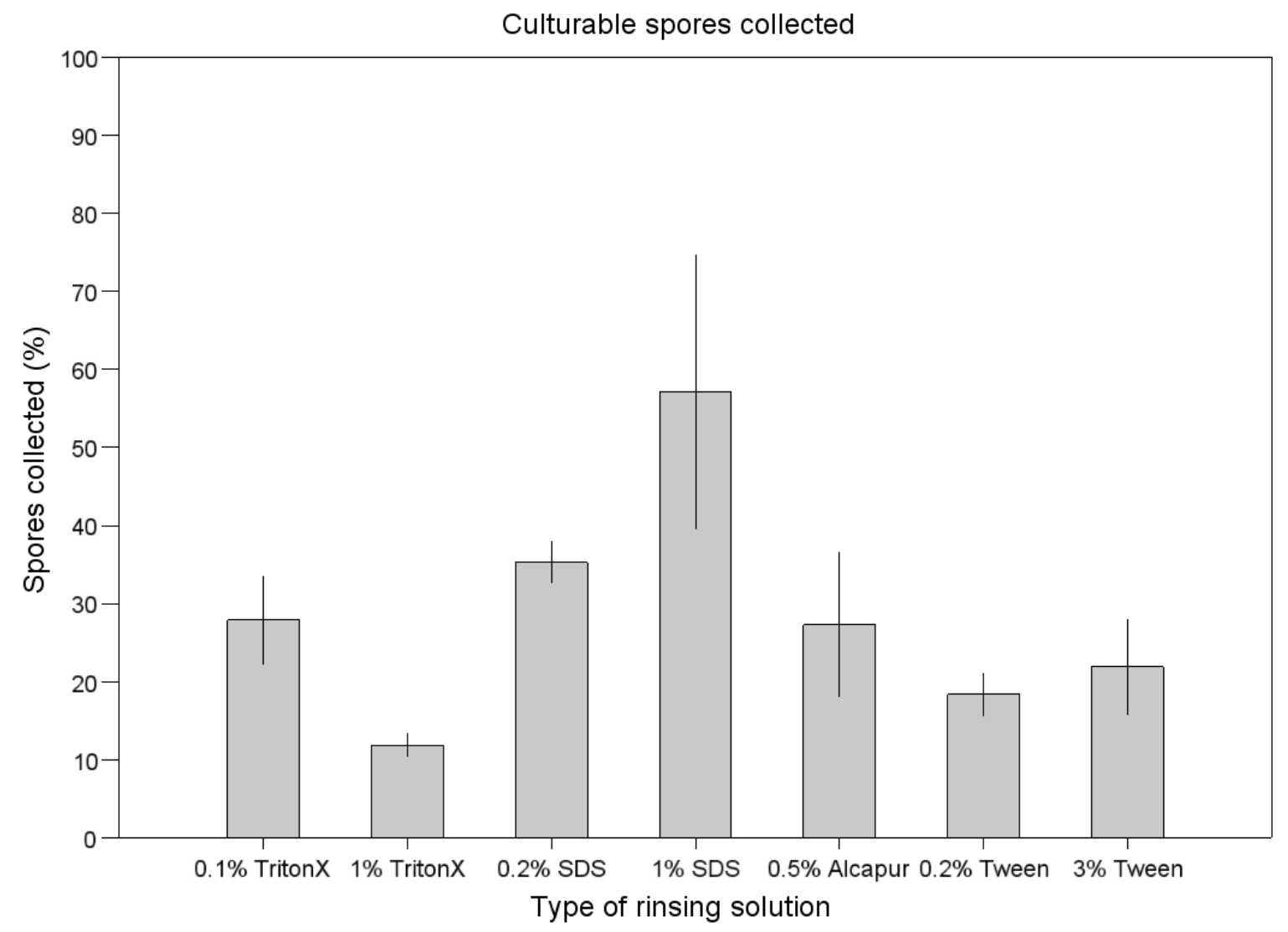

Fig. 5: Efficiency evaluated by using different rinsing solutions. Collected spores were eluted with an injection of $15 \mathrm{ml}$ of different types of tensides after a collection time of three minutes and spore numbers were calculated by plate counting. Error bars indicate standard deviation of three collections. 


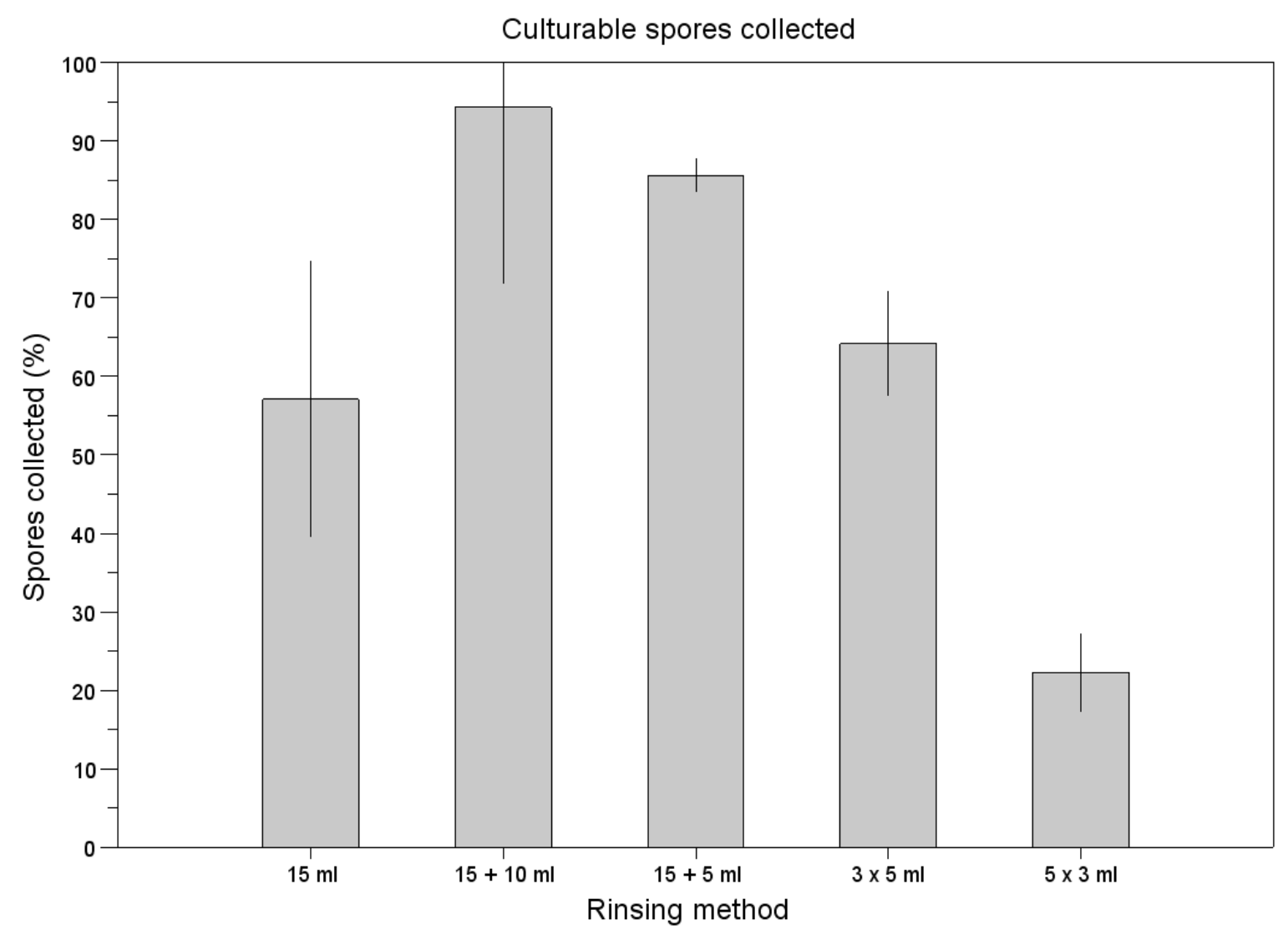

Fig. 6: Effects of different rinsing methods on spore elution with $1 \%$ SDS. Different number and volume of flushes were used as indicated. Numbers of spores were determined by plate counting. Error bars indicate standard deviation of at least two collections. 


\begin{tabular}{|c|c|c|c|c|c|c|}
\hline References & Stage(s) & $\begin{array}{c}\text { Flow Rate } \\
\text { (L/min.) }\end{array}$ & $\begin{array}{l}\text { Applied } \\
\text { Voltage } \\
(\mathbf{k V})\end{array}$ & $\begin{array}{l}\text { Distance } \\
\text { between } \\
\text { electrodes } \\
(\mathrm{cm})\end{array}$ & $\begin{array}{l}\text { Electric } \\
\text { Field } \\
(\mathbf{k V} / \mathrm{cm})\end{array}$ & Aerosols tested \\
\hline Tan et al. 2011 & $\begin{array}{l}\text { Charger stage } \\
\text { Collection stage }\end{array}$ & 1.2 & $+/-20$ & $\begin{array}{l}4.5 \\
\text { (hemispherical } \\
\text { capacitor) }\end{array}$ & $0.23-200$ & $\begin{array}{l}\text { Indoor and outdoor } \\
\text { bacterial aerosols }\end{array}$ \\
\hline $\begin{array}{l}\text { Han et al. } 2010 \\
\text { Han \& Mainelis } 2008\end{array}$ & $\begin{array}{l}\text { Charger stage } \\
\text { Collection stage }\end{array}$ & 10 & -7 & $\begin{array}{l}2.5 \\
\text { (half cylinder) }\end{array}$ & $-2.8^{*}$ & $\begin{array}{l}\text { Bacillus subtilis } \\
\text { Pseudomonas fluorescens }\end{array}$ \\
\hline Han et al. 2009 & $\begin{array}{l}\text { Concentrator stage } \\
\text { Charger stage } \\
\text { Collection stage }\end{array}$ & $\begin{array}{l}1^{\text {st }} \text { stage: } 100 \\
\text { ESP stage: } 3\end{array}$ & 3 & $\begin{array}{c}0.6 \\
\text { (plane } \\
\text { capacitor) }\end{array}$ & $5.0 *$ & $\begin{array}{l}\text { Sodium chloride }(\mathrm{NaCl}) \\
\text { particles and atmospheric } \\
\text { particles }\end{array}$ \\
\hline Han et al. 2009 & $\begin{array}{l}\text { Concentrator stage } \\
\text { Charger stage } \\
\text { Collection stage }\end{array}$ & $\begin{array}{l}1^{\text {st }} \text { stage: } 100 \\
\text { ESP stage: } 3\end{array}$ & 10 & $\begin{array}{c}1 \\
\text { (plane } \\
\text { capacitor) }\end{array}$ & 10.0 & $\begin{array}{l}\text { Sodium chloride }(\mathrm{NaCl}) \\
\text { particles and atmospheric } \\
\text { particles }\end{array}$ \\
\hline Yao et al. 2009 & $\begin{array}{l}\text { No charger } \\
\text { Collection stage }\end{array}$ & 12.5 & $10^{*}$ & $\begin{array}{c}8.0 \\
\text { (plane } \\
\text { capacitor) }\end{array}$ & 1.25 & Allergens and Toxins \\
\hline Sillanpää et al. 2008 & $\begin{array}{l}\text { Concentrator stage } \\
\text { Single stage ESP }\end{array}$ & $\begin{array}{l}1^{\text {st }} \text { stage: } 100 \\
\text { ESP stage: } 1.8\end{array}$ & $18^{*}$ & $\begin{array}{c}3.4 \\
\text { (point to plane) }\end{array}$ & 5.3 & $\begin{array}{l}\text { Latex particles, fluorescent } \\
\text { particles and atmospheric } \\
\text { particles }\end{array}$ \\
\hline $\begin{array}{l}\text { Madsen \& Sharma } \\
2007\end{array}$ & Single stage ESP & 2900 & 2.7 & - & - & Urban street air \\
\hline Yao \& Mainelis 2006 & $\begin{array}{l}\text { No charger } \\
\text { Collection stage }\end{array}$ & 10 & 8 & $\begin{array}{c}1.6 \\
\text { (plane } \\
\text { capacitor) }\end{array}$ & 5.0 & $\begin{array}{l}\text { Indoors and outdoors } \\
\text { particles } \\
\text { Outdoor fungi }\end{array}$ \\
\hline Mainelis et al. 2002 & $\begin{array}{l}\text { Charger stage } \\
\text { Collection stage }\end{array}$ & 4 & $+/-4$ & $\begin{array}{c}0.5 \\
\text { (plane } \\
\text { capacitor) }\end{array}$ & $+/-8.0$ & $\begin{array}{l}\text { Bacillus subtilis } \\
\text { Penicillium brevicompactum } \\
\text { Pseudomonas fluorescens }\end{array}$ \\
\hline Mainelis et al. 1999 & $\begin{array}{l}\text { No charger } \\
\text { Collection stage }\end{array}$ & 1 & - & - & 4.2 & $\begin{array}{l}\text { Bacillus subtilis } \\
\text { Mycobacterium bovis } \\
\text { Pseudomonas fluorescens }\end{array}$ \\
\hline
\end{tabular}

Table 1: Studies on electrostatics precipitators (ESP) designed for the collection of biological materials and their working points; asterisks indicate parameters which were derived from the published data. 